\title{
UM PANORAMA DE ESTUDOS NACIONAIS SOBRE A AQUISIÇÃO DE NOMEAÇÃO EM PROCEDIMENTOS COM EQUIVALÊNCIA DE ESTÍMULOS E USUÁRIOS DE IMPLANTE COCLEAR
}

\section{AN OVERVIEW OF NATIONAL STUDIES ON THE ACQUISITION OF NAMING IN PROCEDURES WITH STIMULUS EQUIVALENCE AND COCHLEAR IMPLANT USERS}

\author{
ÁtILA MOREIRA CEDRO

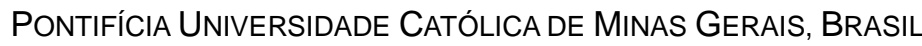 \\ AnNa Christina P. M. PASSARELLI \\ FACULDADE PITÁGORAS, BRASIL \\ EdSON MASSAYUKI HUZIWARA \\ UNIVERSIDADE FEDERAL DE MINAS GERAIS, BRASIL
}

\begin{abstract}
RESUMO
O presente artigo teve por objetivo descrever e analisar, criticamente, o conjunto de experimentos conduzidos por pesquisadores brasileiros a respeito de equivalência de estímulos, nomeação e implante coclear, publicados entre 2008 e 2013. Para tanto, realizou-se um levantamento bibliográfico, em periódicos da área da análise do comportamento e em bancos de teses e dissertações, selecionando-se trabalhos sobre equivalência de estímulos, implante coclear e nomeação. Foram analisados 11 estudos. Após a análise dos estudos, tornou-se possível sugerir que os procedimentos de ensino, comumente aplicados em participantes com implante coclear, foram mais eficientes para estabelecer comportamentos de seleção de figuras e de palavras impressas - ambos considerados repertório receptivo -, do que para estabelecer comportamentos de nomeação de figuras e de palavras impressas, que são comportamentos associados à leitura expressiva. Nesta perspectiva, percebe-se como são necessários avanços tecnológicos nos procedimentos de ensino que se propõem a instalar e manter comportamentos associados à leitura expressiva, a ponto de serem tão eficazes quanto os procedimentos de ensino que instalam e mantêm o repertório receptivo.
\end{abstract}

Palavras chave: equivalência de estímulos, implante coclear, nomeação.

\begin{abstract}
This paper aims to describe and critically analyze the set of experiments conducted by Brazilian researchers on stimulus equivalence, naming (expressive repertoire) and cochlear implants, which were published between 2008 and 2013. To this end, a literature review in journals of Behavior Analysis, and banks of theses and dissertations, selecting work on stimulus equivalence, cochlear implants and naming, was conducted. 11 studies were analyzed. After analyzing the studies, it was possible to suggest that the teaching procedures, more often used with participants with cochlear implants, have been more efficient to establish picture and printed words selection behaviors - both considered receptive repertoire - than to establish naming pictures and printed words behaviors, which are behaviors associated with expressive reading. In this perspective, it became clear how necessary technological advances in teaching procedures that propose to install and maintain behaviors associated with expressive reading, as effective as teaching procedures that install and maintain behaviors associated with receptive reading.
\end{abstract}

Keywords: stimulus equivalence, cochlear implant, naming.

Texto originalmente apresentado como Trabalho de Conclusão de Curso de Especialização em Terapia Comportamental, realizado pelo primeiro autor, sob a orientação da segunda autora. $\mathrm{O}$ terceiro autor auxiliou na escrita do presente artigo. Edson M. Huziwara é membro do Instituto Nacional de Ciência e Tecnologia em Comportamento, Cognição e Ensino (INCT-ECCE), financiado por FAPESP (Processo $n^{\circ}$. 08/57705-8) e CNPq (Processo $n^{\circ}$. 573972/2008-7). A correspondência relativa a este artigo deve ser enviada ao primeiro autor: atila.cedro@gmail.com. 
Uma forma recorrente de surdez neurossensorial profunda está associada à perda, ou lesão, das células ciliadas, que se encontram na cóclea. Nessas situações, em geral, recomenda-se a utilização do implante coclear (Bevilacqua, 1998). O implante coclear é um aparelho eletrônico biomédico capaz de realizar algumas das funções das células ciliadas, dentre elas a de estimular as fibras intactas que permaneceram no nervo auditivo (de Oliveira, 2005, Danieli, 2010; Lima Jr., Rodrigues Jr., Calhau, Calhau, \& Palhano, 2010). Diante da possibilidade de desenvolver o sentido da audição, usuários de implante coclear necessitam de um processo de habilitação auditiva ou, mais especificamente, da aquisição de repertórios comportamentais relacionados tanto ao reconhecimento, quanto à produção de fala inteligível (Almeida, Battaglini, \& Almeida-Verdu, 2009; Golfeto, 2010; Passarelli et al., 2013; Silva \& Araujo, 2007).

Em termos de habilitação auditiva, procedimentos para o ensino de relações condicionais entre estímulos auditivos e desempenhos comportamentais novos, em implantados, têm sido a principal contribuição da Análise Experimental do Comportamento. Um procedimento comumente usado para o ensino dessas relações condicionais é o Matching-to-sample (MTS) ${ }^{1}$. Nesse procedimento, em termos gerais, um estímulo é apresentado como modelo (p. ex., a palavra ditada "tatu"). Uma vez que o participante sinalize ter ouvido a palavra, dois ou mais estímulos de comparação são apresentados (p. ex., uma figura de um tatu e uma figura de um bolo) e o participante é requisitado a escolher uma delas. Consequências diferenciais correlacionadas a respostas corretas (i.e., escolher o estímulo de comparação "figura do tatu" diante do modelo da palavra ditada "tatu") e incorretas (i.e., escolher o comparação "figura do bolo" diante do modelo palavra ditada "tatu") são fornecidas após a emissão de cada resposta de escolha. Assim sendo, uma criança em processo de habilitação auditiva poderia aprender a escolher a figura de um tatu, diante da palavra ditada "tatu", assim como a figura de um bolo, diante da palavra ditada "bolo". Diríamos, portanto, que esta criança aprendeu a relacionar, condicionalmente, nomes ditados e figuras. Podemos supor, ainda, que esta mesma criança seja ensinada a selecionar a palavra escrita TATU, diante da palavra ditada "tatu", assim como a palavra escrita BOLO, diante da palavra ditada "bolo". Nesse caso, ela também aprendeu a relacionar, condicionalmente, nomes ditados e palavras escritas.

Em determinados contextos, apenas o ensino desse limitado conjunto de relações condicionais pode se constituir como condição suficiente para o surgimento de relações condicionais emergentes. Por exemplo, a criança poderá ser capaz de $(i)$ escolher a figura de um bolo, diante da palavra impressa BOLO e, também, (ii) escolher a palavra impressa BOLO, diante da figura bolo (i.e., relações condicionais entre figuras e palavras escritas que não foram diretamente ensinadas). Estas novas relações

\footnotetext{
${ }^{1}$ Emparelhamento de acordo com o modelo, em tradução livre.
}

condicionais, que surgem a partir daquelas anteriormente ensinadas, são parte das evidências necessárias para comprovar a formação de uma classe de estímulos equivalentes (Sidman \& Tailby, 1982).

Para determinar se houve, realmente, a formação de uma classe de estímulos equivalentes, após a realização de um treino condicional como o descrito anteriormente, avalia-se a existência de três propriedades relacionais entre os estímulos: a reflexividade, a simetria e a transitividade (Sidman \& Tailby, 1982). A reflexividade é demonstrada pela emergência de uma relação condicional entre qualquer estímulo utilizado, durante o treino, e outro estímulo idêntico a ele. Por exemplo, escolher a palavra impressa BOLO, diante de outra palavra impressa BOLO e, também, escolher a figura de um bolo, diante de outra figura de um bolo. A simetria é demonstrada pela emergência de uma relação condicional, nas situações em que as funções de modelo e comparação são invertidas. A título de exemplo, no treino hipotético descrito anteriormente, palavras ditadas eram utilizadas como modelos e palavras impressas eram apresentadas como comparações. Assim, a simetria seria comprovada se o desempenho dos participantes se mantivesse estável, diante de tentativas em que palavras impressas fossem apresentadas como modelos e palavras ditadas fossem apresentadas como comparações. A transitividade, por sua vez, é demonstrada pela emergência de uma relação condicional entre dois estímulos que não foram diretamente relacionados durante o treino, mas que foram relacionados a um terceiro elemento comum. Utilizando o exemplo hipotético anterior, a palavra impressa BOLO e a figura de um bolo não foram diretamente relacionadas durante o treino, mas ambos os estímulos foram condicionalmente relacionados à palavra ditada "bolo" (de Rose, 1993).

De acordo com os pressupostos da análise do comportamento, a habilidade de formar classes de equivalência pode ser fundamental para o uso funcional da linguagem, para a leitura com compreensão e muitos outros comportamentos, descritos como simbólicos (de Rose, 1993; Sidman, 1971, 1994, 2000). Para além das relações condicionais emergentes, os estímulos que compõem uma classe de equivalência podem, também, adquirir controle sobre a emissão de respostas de vocalização. Por exemplo, uma criança submetida ao treino descrito, anteriormente, pode passar a vocalizar a palavra "bolo" tanto diante da figura bolo, quanto diante da palavra impressa BOLO. Nesta perspectiva, as vocalizações apresentadas pelos participantes também são frutos da formação de classes de estímulos equivalentes, pois o comportamento de nomear as figuras e as palavras impressas surge em função das relações condicionais diretamente ensinadas (Sidman, 1994). Isto é notável para o trabalho de habilitação auditiva. Quando uma criança escolhe a palavra impressa BOLO, diante da figura de um bolo ou quando seleciona a palavra impressa BOLO, diante da palavra ditada "bolo", ela aprende pré-requisitos rudimentares necessários para desenvolver a leitura, com compreensão, e para interpretar estímulos recebidos por meio do implante coclear. Da mesma forma, quando a 
criança emite a vocalização "bolo", diante da palavra impressa BOLO ou diante da figura de um bolo, ela demonstra habilidades necessárias para o desenvolvimento da nomeação de palavras e da produção de fala inteligível (Almeida-Verdu, 2004; Brazarotto, 2008; Passarelli et al., 2013).

Ao considerar a relevância científica e social de procedimentos de ensino utilizados para a habilitação auditiva, bem como os importantes avanços provenientes de pesquisas realizadas em âmbito nacional, o presente artigo teve por objetivo descrever e analisar, criticamente, o conjunto de experimentos conduzidos por pesquisadores brasileiros a respeito de equivalência de estímulos, nomeação e implante coclear e que foram publicados entre 2008 e 2013. No processo inicial de busca, foram consultados volumes de periódicos, com alta probabilidade de publicação de trabalhos de interesse, além de capítulos de livros e bancos de dissertações e teses de Programas de Pós-Graduação. Por fím, alguns estudos localizaram-se dentre as referências bibliográficas dos estudos identificados, neste primeiro momento (Goyos et al, 2009).

Os periódicos e bancos de teses e dissertações consultados estão listados abaixo, bem como a quantidade de trabalhos encontrados em cada um deles:

- Journal of Applied Behavior Analysis (JABA) nenhum estudo encontrado;

- Journal of Experimental Analysis of Behavior (JEAB) - um estudo encontrado;

- Revista Brasileira de Análise do Comportamento (ReBAC) - um estudo encontrado;

- Revista Latina de Análise do Comportamento Acta Comportamentalia - três estudos encontrados;

- Revista da Sociedade Brasileira de Psicologia, "Temas em Psicologia" - um estudo encontrado;

- Volumes da coleção "Sobre Comportamento $e$ Cognição" - um estudo encontrado;

- Biblioteca Digital de Teses e Dissertações da Faculdade de Ciências da Universidade Estadual Paulista (UNESP-Bauru) - um estudo encontrado;

- Biblioteca Digital de Teses e Dissertações da Universidade Federal de São Carlos (Bco/UFSCar) dois estudos encontrados.

Os descritores utilizados para o levantamento dos estudos foram: equivalência de estímulos, nomeação e implante coclear. A partir dos itens encontrados, neste processo inicial de busca, os estudos foram incluídos/excluídos da análise realizada, no presente trabalho, de acordo com os critérios abaixo:

- $\quad$ ter sido publicado entre os anos de 2008 e 2013;

- ter sido realizado no Brasil;

- ter como participantes indivíduos com implante coclear;

- $\quad$ ter utilizado o matching-to-sample para o ensino das relações condicionais entre estímulos visuais e entre estímulos visuais e sonoros;

- ter aplicado testes de nomeação de palavras impressas e/ou de figuras.

Similar ao método utilizado por Goyos et al (2009), cada um dos trabalhos encontrados na busca inicial foi avaliado por, pelo menos, duas pessoas, considerando os termos da adequação aos critérios propostos. Posteriormente, o número de julgamentos concordantes foi dividido pelo número total de trabalhos encontrados e multiplicado por 100 (Hall, 1974). Obteve-se um percentual de $100 \%$ de concordância. Todos os estudos encontrados atendiam aos critérios propostos.

Assim, foram selecionados os seguintes trabalhos:

- Almeida-Verdu, dos Santos, de Souza e Bevilacqua (2008);

- Almeida-Verdu, Huziwara, de Souza, de Rose, Bevilacqua, Lopes Jr., Alves e McIlvane (2008);

- Almeida-Verdu, Bevilcqua, de Souza e de Souza (2009);

- Almeida-Verdu, Matos, Battaglini, Bevilacqua e de Souza (2012);

- Anastácio-Pessan (2011);

- Battaglini, Almeida-Verdu e Bevilacqua (2013);

- de Souza, Golfeto, Almeida-Verdu, Battaglini, Bevilacqua e de Oliveira (2010);

- de Souza, Almeida-Verdu e Bevilacqua (2013);

- Golfeto (2010);

- Oliveira (2013);

- Passarelli, de Oliveira, Golfeto, Cardinali, de Rezende e Fenner (2013).

\section{PROCEDIMENTOS DE ENSINO E TESTES DE NOMEAÇÃO}

Uma primeira característica é que a maioria dos estudos analisados ensinou relações condicionais que envolviam palavras ditadas (estímulos auditivos), figuras e palavras impressas (estímulos visuais). Para tanto, os estudos utilizaram o procedimento de MTS e, além disso, alguns deles utilizaram o MTS associado à modelagem do controle de estímulos (fading-out) e/ou ao ensino, por exclusão. Houve, também, experimentos nos quais ocorreu o ensino de comportamento ecoico.

Para realizar os testes de nomeação, característica comum a todos os experimentos, apresentaram-se figuras ou palavras impressas ao participante e, em seguida, perguntava-se "o que é isto?". As consequências para respostas corretas e incorretas não eram apresentadas, nessas tentativas. As respostas emitidas pelos participantes eram categorizadas entre nomeação com correspondência ponto a ponto, nomeação sem correspondência ponto a ponto (ou parcial), nomeação sem correspondência e não respostas. As vocalizações consideradas com correspondência ponto a ponto foram aquelas nas quais todos os fonemas da palavra foram emitidos na ordem considerada correta. Na nomeação sem correspondência ponto a ponto, o participante foi capaz de emitir uma vocalização com troca e/ou supressão de alguns fonemas. $\mathrm{Na}$ nomeação sem correspondência, o participante apresentava uma vocalização que não correspondia em nada à palavra ditada. Havia, ainda, casos em que o participante não apresentava vocalização alguma, quando requisitado (Almeida-Verdu, Huziwara et al., 2008; Almeida-Verdu, dos Santos et al., 2008; Almeida-Verdu et al., 2009; Almeida-Verdu et al., 2012; Anastácio-Pessan, 2011; Battaglini et al., 2013; de Souza et al., 2010; de 
Souza et al., 2013; Golfeto, 2010; Oliveira, 2013; Passarelli et al., 2013).

Nos procedimentos com fading-out, o controle exercido pela similaridade física entre estímulos visuais foi utilizado como base para o ensino das discriminações auditivo-visuais. Nesses procedimentos, o estímulo modelo era composto por uma parte visual e outra parte auditiva. Por exemplo, para ensinar uma criança a escolher a figura de um tatu, diante da palavra ditada "tatu", apresentavam-se, como modelo, nas primeiras tentativas de ensino, tanto a figura do tatu, como a palavra ditada "tatu". Em tentativas posteriores, a figura apresentada como parte do modelo ia sendo esvanecida, gradualmente. Dessa forma, apenas a palavra ditada era apresentada, nas últimas tentativas de ensino. A partir da retirada gradual da parte visual do modelo, esperava-se que a parte auditiva fosse, paulatinamente, adquirindo controle sobre $\mathrm{o}$ comportamento de selecionar a figura correspondente (Catania, 1999). Os estudos de Almeida-Verdu, Huziwara et al. (2008) e de Souza et al. (2013) utilizaram o fadingout tanto para fases de pré-treino, quanto para o estabelecimento da linha de base. Os demais estudos que se valeram deste procedimento (Almeida-Verdu et al., 2012; Anastácio-Pessan, 2011; Bataglinni et al., 2013; Golfeto, 2010, Passarelli et al., 2013), aplicaram-no, apenas, nas fases de pré-treino.

Dentre os estudos que utilizaram o fading-out para o estabelecimento da linha de base, somente no estudo de Almeida-Verdu, Huziwara et al. (2008) Experimento 2 - observou-se $100 \%$ de acertos nos testes de nomeação de figuras, desempenho exibido por um participante. No estudo de Souza et al. (2013), dois participantes obtiveram $78 \%$ de acertos, porém nenhum deles atingiu $100 \%$ de acertos nos testes de nomeação. Ao comparar a quantidade de tentativas programadas entre os dois estudos, nota-se que Almeida-Verdu, Huziwara et al. - Experimentos 1 e 2 - programaram 144 tentativas, enquanto de Souza et al. programaram 48 tentativas de ensino. Contudo, de Souza et al. também programaram 48 tentativas para o ensino de ecoico (os dados sobre o ensino de ecoico serão discutidos adiante). Também vale ressaltar que, em de Souza et al., foram ensinadas três relações condicionais, enquanto que, em Almeida-Verdu, Huziwara et al., foram ensinadas seis relações. A Tabela 1 apresenta um resumo dos principais resultados encontrados.

Nos procedimentos baseados no ensino por exclusão (Dixon, 1977), as relações condicionais aprendidas previamente são utilizadas como linha de base para a aquisição de novas relações condicionais. Por exemplo, considere que um participante aprendeu a relacionar, condicionalmente, a palavra ditada "bolo" e a palavra escrita BOLO. Para ensinar uma relação entre a palavra ditada "tatu" e a palavra escrita TATU, poder-se-ia apresentar a palavra ditada "tatu" como modelo e os estímulos comparações seriam as palavras escritas BOLO (estímulo definido, ensinado previamente) e TATU (estímulo indefinido, não ensinado). O participante poderia excluir o estímulo comparação definido BOLO e escolher o outro estímulo comparação apresentado - nesse caso, TATU. Os estudos analisados que utilizaram o procedimento de exclusão, nas fases de ensino das relações condicionais, foram Almeida-Verdu, Huziwara et al., (2008) - Experimento 3, Almeida-Verdu et al. (2012), Anastácio-Pessan (2011), Battaglini et al. (2013) e Oliveira (2013).

Tabela 1. Comparação entre os experimentos que aplicaram o fading-out, durante o estabelecimento da linha de base. São apresentados: identificação do estudo; quantidade de tentativas realizadas, por cada participante, durante a linha de base*; resultados dos testes de nomeação.

\begin{tabular}{lll}
\hline Identificação & $N^{\circ}$ de tentativas & $\begin{array}{l}\text { Testes de } \\
\text { nomeação }\end{array}$ \\
\hline Almeida-Verdu, & $(144$ tentativas)* & $P 1: 80 \%$ \\
Huziwara et al. (2008) & $P 1: 288$ & $P 2: 50 \%$ \\
- experimento 1. & $P 2: 378$ & $P 3: 60 \%$ \\
& $P 3: 396$ & $P 4: 60 \%$ \\
& $P 4: 288$ & \\
Almeida-Verdu, & $(144$ tentativas)* & $P 1: 30 \%$ \\
Huziwara et al. (2008) & $P 1: 486$ & $P 2: 100 \%$ \\
- experimento 2. & $P 2: 432$ & $P 3: 30 \%$ \\
& $P 3: 360$ & \\
De Souza et al. (2013) & $(48$ tentativas)* & $P 1: 78 \%$ \\
- experimento 3. & $P 1: 48$ & $P 2: 22 \%$ \\
& $P 2: 48$ & $P 3: 78 \%$ \\
& $P 3: 48$ & $P 4: 33 \%$ \\
& $P 4: 133$ &
\end{tabular}

* O número, entre parênteses, apresenta a quantidade de tentativas necessárias para concluir o procedimento, caso não fossem cometidos erros.

Quando analisados os estudos que aplicaram o ensino por exclusão, um participante no Experimento 3 de Almeida-Verdu, Huziwara et al. (2008) e um participante no estudo de Battaglini et al. (2013) obtiveram 100\% de acertos, nos testes de nomeação. Em Anástacio-Pessan (2011), nota-se que alguns participantes apresentaram variações entre $33 \%$ e $100 \%$ de acertos, nos testes de nomeação. No estudo de Oliveira (2013), os resultados dos participantes também variaram, contudo nenhum atingiu $100 \%$ de acertos. No que diz respeito ao número de tentativas programadas para o estabelecimento da linha de base, também foram observadas variações entre os estudos: em Almeida-Verdu, Huziwara et al.- Experimento 3 -, foram programadas 148 tentativas para o ensino de seis relações condicionais; em Almeida-Verdu et al., foram programadas 36 tentativas para o ensino de três relações condicionais; Anastácio-Pessan programou 168 tentativas para o ensino de 16 relações condicionais; em Battaglini et al., foram programadas 90 tentativas para o ensino de seis relações condicionais; Oliveira programou 128 tentativas para o ensino de oito relações condicionais. Nota-se que, em alguns casos, a variação na quantidade de tentativas programadas, observada entre os estudos, pode estar associada à quantidade de relações condicionais que eram ensinadas em cada estudo. Nessa perspectiva, quanto maior o número de relações condicionais ensinadas, maior foi a quantidade de tentativas programadas para o estabelecimento da linha de base. A Tabela 2 apresenta um resumo dos principais resultados encontrados. 
Tabela 2. Comparação entre os experimentos que aplicaram o ensino por exclusão. São apresentados: identificação do estudo; quantidade de tentativas emitidas, por cada participante, durante a linha de base*; resultados dos testes de nomeação**.

\begin{tabular}{|c|c|c|}
\hline Identificação & $\mathrm{N}^{\mathrm{o}}$ tentativas & Testes de nomeação \\
\hline Almeida-Verdu, Huziwara et al. (2008) - experimento 3 & $\begin{array}{l}\text { (148 tentativas)* } \\
\text { P1: } 148 \\
\text { P2: } 182 \\
\text { P3: } 164\end{array}$ & $\begin{array}{l}P 1: 100 \% \\
P 2: 30 \% \\
P 3: 65 \%\end{array}$ \\
\hline Almeida-Verdu et al. (2012) & $\begin{array}{l}\text { (36 tentativas)* } \\
P 1: 51 \\
P 2: 36 \\
P 3: 36 \\
P 4: 36\end{array}$ & $\begin{array}{l}\text { P1: } 44,4 \% \\
P 2: 88,8 \% \\
P 3: 44,4 \% \\
P 4: 44,4 \%\end{array}$ \\
\hline Anastácio-Pessan (2011) & $\begin{array}{l}\text { (168 tentativas)* } \\
\text { P1: } 192 \\
\text { P2: } 168 \\
\text { P3: } 168 \\
\text { P4: } 168 \\
\text { P5: } 276 \\
\text { P6: } 204\end{array}$ & $\begin{array}{l}\text { P1: } 66 ; 7 \% * * \\
\text { P2: } 100 \% * * \\
\text { P3: } 66 ; 7 \% * * \\
\text { P4: } 100 \% * * \\
\text { P5: } 100 \% * * \\
\text { P6: } 100 \% * *\end{array}$ \\
\hline Battaglini et al. (2013) & $\begin{array}{l}\text { (90 tentativas)* } \\
P 1: 258 \\
P 2: 177 \\
P 3: 144 \\
P 4: 120 \\
P 5: 90\end{array}$ & $\begin{array}{l}P 1: 22 \% \\
P 2: 11 \% \\
P 3: 11 \% \\
P 4: 33 \% \\
P 5: 100 \%\end{array}$ \\
\hline Oliveira (2013) & $\begin{array}{l}(128 \text { tentativas })^{*} \\
P 1: 256 \\
P 2: 176 \\
P 3: 160 \\
P 4: 176\end{array}$ & $\begin{array}{l}P 1: 75 \% * * \\
P 2: 88 \% * * \\
P 3: 25 \% * * \\
P 4: 62 \% * *\end{array}$ \\
\hline
\end{tabular}

* O número entre parênteses apresenta a quantidade de tentativas necessárias para concluir o procedimento, caso não fossem cometidos erros.

** Nos casos em que o procedimento previa a realização de vários testes de nomeação, apenas a maior porcentagem de acertos foi apresentada.

\section{ENSINO DO ECOICO E TESTES DE NOMEAÇÃO}

Nas tarefas de ensino do comportamento ecoico, uma palavra era ditada e, em seguida, a criança deveria emitir a vocalização correspondente à palavra ditada. Nos casos em que a criança não apresentava a vocalização, com correspondência ponto a ponto com a palavra ditada, forneciam-se pistas orofaciais, como forma de procedimento corretivo. Nos estudos de Almeida-Verdu, dos Santos et al. (2008) e AlmeidaVerdu et al. (2009), as pistas orofaciais eram concedidas pelo próprio experimentador, ao passo que, no estudo de Souza et al. (2013), as pistas orofaciais eram apresentadas por meio de um vídeo. Quando comparadas as quantidades de tentativas programadas para o ensino de ecoico em cada estudo, torna-se possível observar uma variação considerável em dois dos três estudos citados. Especificamente, em Almeida-Verdu et al., foram programadas 134 tentativas de ensino, na Condição 1 e apenas nove tentativas, na Condição 2. Em de Souza et al., foram programadas 48 tentativas para o ensino de comportamento ecoico. Vale ressaltar que, similar ao que foi observado dentre os estudos que aplicaram o fading-out e o ensino por exclusão, a variação na quantidade de tentativas para o ensino do comportamento ecoico, observada entre os estudos, pode ter ocorrido em função do número de relações condicionais ensinadas em cada estudo. Enquanto em de Souza et al. eram ensinadas três relações condicionais, em Almeida-Verdu et al. eram ensinadas seis relações condicionais.

A comparação entre os estudos que realizaram o ensino de comportamento ecoico, aliado ao ensino das relações condicionais, demonstra que, em dois dos três estudos descritos, ao menos um participante apresentou $100 \%$ de acertos nos testes de nomeação (AlmeidaVerdu, dos Santos et al., 2008; de Souza et al., 2013). Em de Souza et al., é interessante notar que, antes do ensino do comportamento ecoico, nenhum dos participantes havia apresentado $100 \%$ de acertos, nos testes de nomeação. Após o ensino do ecoico, no entanto, um participante apresentou $100 \%$ de acertos, nos testes de nomeação. A Tabela 3 apresenta os principais resultados obtidos, nos referidos estudos. 
Tabela 3. Comparação entre os experimentos que realizaram o ensino de comportamento ecoico. São apresentados: identificação do estudo; quantidade de tentativas emitidas, por cada participante, durante a linha de base*; resultados dos testes de nomeação**.

\begin{tabular}{|c|c|c|}
\hline Identificação & $\mathrm{N}^{\mathrm{o}}$ de tentativas & Testes de nomeação \\
\hline $\begin{array}{l}\text { Almeida-Verdu, } \\
\text { dos Santos et al. } \\
\text { (2008) }\end{array}$ & $\begin{array}{l}\text { Não informado em } \\
\text { quantidades }\end{array}$ & $\begin{array}{l}\text { P.x: }>80 \% \\
P . y: 100 \% \text {. } \\
\text { (Foram apresentados } \\
\text { resultados de dois } \\
\text { participantes). }\end{array}$ \\
\hline $\begin{array}{l}\text { Almeida-Verdu et } \\
\text { al. (2009) }\end{array}$ & $\begin{array}{l}(134 \text { tentativas }-P 1 \text { e } \\
P 2)^{*} \\
(9 \text { tentativas }-P 3 e \\
P 4)^{*} \\
P 1: 228 \\
P 2: 198 \\
P 3: 18 \\
P 4: 18\end{array}$ & $\begin{array}{l}P 1: 85 \% \\
P 2: 83 \% \\
P 3: 80 \% \\
P 4: 76 \%\end{array}$ \\
\hline $\begin{array}{l}\text { de Souza et al. } \\
(2013)- \\
\text { experimento } 3 .\end{array}$ & $\begin{array}{l}\text { (48 tentativas)* } \\
P 1: 48 \\
P 2: 48 \\
P 3: 48 \\
P 4: 91\end{array}$ & $\begin{array}{l}P 1: 88,8 \% \\
P 2: 66,6 \% \\
P 3: 100 \% \\
P 4: 55 \%\end{array}$ \\
\hline
\end{tabular}

* O número entre parênteses apresenta a quantidade de tentativas necessárias para concluir o procedimento, caso não fossem cometidos erros.

** Nos casos em que o procedimento previa a realização de vários testes de nomeação, apenas a maior porcentagem de acertos foi apresentada.

Os resultados dos testes de nomeação de Almeida-Verdu, dos Santos et al. (2008), Almeida-Verdu et al. (2009) e de Souza et al. (2013) demonstram um aumento dos escores obtidos pelos participantes, quando comparados aos atingidos antes das fases de ensino. $\mathrm{O}$ aumento dos escores, segundo os autores, deve-se ao ensino direto de ecoico e de nomeação com correspondência ponto a ponto com a palavra ditada. Esses resultados sugerem a importância da apresentação de pistas orofaciais, associadas ao ensino de comportamento ecoico. As pistas orofaciais permitem, ao participante, aprender o comportamento vocal com correspondência ponto a ponto. Além disso, é possível ensinar, simultaneamente, comportamentos de nomeação e de seleção de figuras e palavras impressas, por meio de métodos específicos que abordem o ensino direto dos comportamentos ecoico, de nomeação e de reconhecimento de palavras. Nesta perspectiva, os indivíduos implantados podem se beneficiar de formas de ensino mais ágeis e eficientes (Almeida-Verdu, dos Santos et al., 2008; Almeida-Verdu et al., 2009; de Souza et al., 2013).

Apesar de não terem planejado o ensino de comportamentos ecoicos, Oliveira (2013) e Passarelli et al. (2013) utilizaram vídeos similares aos usados por de Souza et al. (2013) . No estudo de Oliveira, esses vídeos serviram como estímulos visuais para o ensino de relações condicionais entre movimentos orofaciais e figuras. Nesse caso, os vídeos não tinham som, só apresentavam uma pessoa realizando os movimentos orofaciais que serviram de modelo. No estudo de Passarelli et al., entretanto, quando determinados participantes cometiam algum erro durante o estabelecimento da linha de base, seguia-se uma tentativa em que um vídeo era apresentado como estímulo modelo. Neste vídeo, havia uma pessoa ditando uma palavra (o estímulo modelo da tentativa em que ocorreu o erro) e, portanto, fornecendo pistas orofaciais. No caso, após uma tentativa com pistas orofaciais, independentemente de erro ou acerto, apresentava-se uma nova tentativa.

\section{EQUIVALÊNCIA DE ESTÍMULOS E TESTES DE NOMEAÇÃO}

Dentre os estudos que aplicaram o fading-out, nas fases de ensino, em Almeida-Verdu, Huziwara et al. (2008) - Experimento 1 -, todos os participantes atingiram $100 \%$ de acertos, nos testes de equivalência. No experimento 2, de Almeida-Verdu, Huziwara et al., dois participantes obtiveram $100 \%$ de acertos, nos testes de equivalência. Ao comparar os resultados dos dois experimentos, talvez seja possível dizer que os participantes pós-linguais (crianças acometidas pela deficiência auditiva, após a aquisição de linguagem) tendem a demonstrar melhores desempenhos, em testes de equivalência, se comparados aos participantes prélinguais (crianças acometidas pela deficiência auditiva, antes da aquisição de linguagem).

Nos estudos em que foi utilizado o ensino por exclusão para o estabelecimento da linha de base, observaram-se elevados desempenhos, nos testes de equivalência. Em quatro, dos cinco estudos que aplicaram o ensino por exclusão, a maioria dos participantes obtiveram $100 \%$ de acertos, nos testes de equivalência. Contudo, em Battaglini et al (2013), dois participantes apresentaram $78 \%$ de acertos, nos referidos testes. Em Almeida-Verdu, Huziwara et al. (2008) - Experimento 3, dois participantes atingiram $100 \%$ de acertos, após uma segunda exposição aos testes de equivalência. Na primeira exposição aos testes de equivalência, estes participantes atingiram $90 \%$ de acertos. A partir de tais resultados, talvez seja possível dizer que o ensino por exclusão, quando aplicado em participantes com implante coclear, mostra-se eficaz para o ensino de relações condicionais entre palavras ditadas/impressas e figuras.

No que diz respeito aos resultados dos testes de equivalência, dos estudos que ensinaram o comportamento ecoico, percebe-se uma maioria de participantes que demonstraram a formação de classes de equivalência. Observa-se exceção no estudo de Almeida-Verdu et al. (2009), em que um participante demonstrou $100 \%$ de acertos, apenas após a oitava exposição aos testes, e outro participante, que demonstrou $97 \%$ de acertos, após a quinta exposição aos testes de equivalência. Quando verificada em conjunto, a análise dos resultados dos testes de equivalência sugere que o ensino de comportamento ecoico, associado ao ensino de relações condicionais e aplicado em participantes com implante coclear, revela- 
se eficaz para estabelecer relações condicionais entre palavras ditadas, palavras impressas e figuras.

A Tabela 4 sumariza os principais resultados apresentados, durante a descrição dos experimentos. É possível observar que três, dentre os 11 estudos analisados, propuseram treinos ecoicos para os seus participantes. Além disso, também é possível observar que, em sete dos 11 estudos, todos os participantes apresentaram $100 \%$ de acertos, nos testes para verificar a formação de classes de equivalência.

Tabela 4. Resumo da Comparação entre Experimentos. São apresentados: a identificação do experimento; a ocorrência, ou não, de treino ecoico; a quantidade de participantes; a quantidade de participantes que atingiram $100 \%$, nos testes de formação de classes e a quantidade de participantes que atingiram 100\%, nos testes de nomeação.

\begin{tabular}{|c|c|c|c|c|}
\hline Experimentos & Ecoico & Participantes & Equivalência & Nomeação \\
\hline $\begin{array}{l}\text { Almeida-Verdu, Huziwara et al. (2008), } \\
\text { Exp.1 }\end{array}$ & Não & Quatro & Quatro & Zero \\
\hline $\begin{array}{l}\text { Almeida-Verdu, Huziwara et al. (2008), } \\
\text { Exp. } 2\end{array}$ & Não & Três & Dois & $\mathrm{Um}$ \\
\hline $\begin{array}{l}\text { Almeida-Verdu, Huziwara et al. (2008), } \\
\text { Exp.3 }\end{array}$ & Não & Três & Três & Um \\
\hline Almeida-Verdu, dos Santos et al. (2008) & Sim & Seis & Seis & $\mathrm{Um}$ \\
\hline Almeida-Verdu et al. (2009) & Sim & Quatro & Quatro & Zero \\
\hline Passarelli et al. (2013) & Não & Cinco & Quatro & Dois \\
\hline Almeida-Verdu et al. (2012) & Não & Quatro & Não se aplica & Zero \\
\hline Battaglini et al. (2013) & Não & Cinco & Três & Um \\
\hline de Souza et al. (2010). Exp.1 & Não & Sete & Sete & Não Informado \\
\hline de Souza et al. (2013). Exp. 1 & Sim & Quatro & Não se aplica & $\mathrm{Um}$ \\
\hline Golfeto (2010). Exp.1 & Não & Dois & Dois & Dois \\
\hline Anastácio-Pessan (2010) & Não & Seis & Seis & $\mathrm{Um}$ \\
\hline Oliveira (2013) & Não & Quatro & Quatro & Zero \\
\hline
\end{tabular}

Entretanto, apenas no experimento realizado por Golfeto (2010), todos os participantes apresentaram 100\%, nos testes de nomeação de figuras. Observa-se, de forma clara, a emergência da nomeação para a considerável maioria dos participantes, mas as porcentagens de acertos variam muito e estão evidentemente abaixo daquelas observadas para a formação de classes de equivalência.

\section{ANÁLISE DETALHADA DOS RESULTADOS OBTIDOS EM TESTES DE NOMEAÇÃO}

Almeida-Verdu, Huziwara et al. (2008) conduziram quatro experimentos, dentre os quais três foram seguidos por testes de nomeação. O primeiro experimento foi conduzido com quatro crianças póslinguais e foram utilizadas três palavras sem sentido e dois conjuntos com três formas abstratas coloridas. Assim sendo, a mesma palavra sem sentido foi associada a duas formas abstratas coloridas diferentes. Durante os testes de nomeação, cada uma das formas coloridas era apresentada, por duas vezes, na tela do computador, a fim de que o participante a nomeasse. Um mesmo nome deveria ser dito para duas figuras diferentes, conforme estabelecido na linha de base. Dentre os quatro participantes submetidos ao procedimento, dois deles acertaram seis, em 12 tentativas (50\% de acertos); um participante acertou sete tentativas (aproximadamente, 60\% de acertos) e um participante acertou dez tentativas ( $83,3 \%$ de acertos).

O segundo experimento descrito, em AlmeidaVerdu, Huziwara et al. (2008), foi bastante similar ao primeiro. A diferença estava relacionada à característica dos participantes. No segundo experimento, participaram três crianças pré-linguais, com implante coclear. Além disso, para um dos participantes, utilizaram-se palavras conhecidas da língua portuguesa, figuras representacionais das palavras e figuras coloridas abstratas, para condução das fases de ensino e testes. Dois participantes acertaram quatro, das 12 tentativas de nomeação (aproximadamente, $33 \%$ de acertos, incluindo o participante que realizou o procedimento com palavras da língua portuguesa e suas figuras representacionais). O terceiro participante obteve $100 \%$ de acertos. 
No terceiro experimento, descrito em AlmeidaVerdu, Huziwara et al. (2008), participaram três crianças, deficientes auditivas pré-linguais, com implante coclear. Foram utilizadas três palavras da língua portuguesa e dois conjuntos de figuras. Um dos conjuntos era de formas coloridas abstratas e o outro era de figuras representacionais das palavras, em português. Os testes de nomeação foram iguais aos dos experimentos anteriores. $\mathrm{O}$ primeiro participante acertou quatro, em 12 tentativas (33\% de acertos); o segundo participante acertou oito tentativas $(66 \%$ de acertos) e o terceiro participante acertou 12 tentativas (100\% de acertos). Analisados em conjunto, os resultados obtidos nesses experimentos parecem indicar que o desempenho apresentado, nos testes de nomeação, foi similar para crianças com deficiência auditiva pré ou pós-lingual. Entretanto, vale ressaltar que as tarefas realizadas pelas crianças com deficiência auditiva pós-lingual apresentavam, tão somente, palavras sem sentido e figuras abstratas, enquanto que as tarefas realizadas por crianças com deficiência auditiva prélingual apresentavam palavras e figuras conhecidas.

Almeida-Verdu, dos Santos et al. (2008) contaram com a participação de seis indivíduos implantados, todos com deficiência auditiva pré-lingual. Foram utilizadas três palavras da língua portuguesa (impressas e ditadas), três figuras representacionais das palavras e três figuras abstratas. Foram duas condições de ensino: na Condição 1, o comportamento ecoico foi ensinado juntamente com as relações condicionais entre palavra ditada e figura; na Condição 2, o ensino do comportamento ecoico ocorreu antes do estabelecimento das relações condicionais. Nos pré-testes de nomeação, foram apresentadas, apenas, as três figuras representacionais; nos pós-testes de nomeação, foram apresentadas tanto as figuras representacionais, quanto as figuras abstratas. As porcentagens de acertos para essas tarefas foram apresentadas, unicamente, para dois dos participantes. $\mathrm{O}$ primeiro participante, exposto à Condição 1 , apresentou $60 \%$ de acertos, no pré-teste e $80 \%$ de acertos, no pós-teste. O segundo participante, exposto à Condição 2 , apresentou $5 \%$ de acertos, no préteste e $100 \%$ de acertos, no pós-teste de nomeação. Portanto, apesar do número reduzido de participantes, cujos dados foram apresentados, a análise dos resultados parece sugerir que o treino ecoico, realizado antes do estabelecimento das relações condicionais, foi mais eficaz quando comparado ao treino ecoico realizado simultaneamente ao estabelecimento de tais relações.

Almeida-Verdu et al. (2009) conduziram um experimento muito similar a Almeida-Verdu, dos Santos et al. (2008), no que diz respeito às fases de pré-teste, ao estabelecimento da linha de base e aos pós-testes. A diferença está no número de participantes que, no caso de Almeida-Verdu et al., foram quatro crianças implantadas, todas deficientes auditivas pré-linguais. Os resultados indicam que as participantes A e B, expostas ao ensino de ecoico, juntamente com o ensino das relações condicionais, emitiram, respectivamente, $33 \%$ e $64 \%$ de vocalizações corretas, no pré-teste e $85 \%$ e $83 \%$ de vocalizações corretas, no pós-teste. Os participantes C e D, que receberam o treino de ecoico, antes do ensino das relações condicionais, apresentaram $60 \%$ e $67 \%$ de vocalizações corretas, no pré-teste e, respectivamente, $80 \%$ e $76 \%$ de vocalizações corretas, no pós-teste. A análise dos resultados sugere que a realização do treino ecoico, juntamente com o treino das relações condicionais, para os participantes A e B, não resultou em maiores porcentagens de acertos, nos testes de nomeação, quando comparados aos participantes $\mathrm{C}$ e $\mathrm{D}$, que realizaram o treino de ecoico, antes do treino das relações condicionais.

Do estudo de Passarelli et al. (2013), participaram cinco indivíduos implantados, todos deficientes auditivos pré-linguais. Foram aplicados dois problemas de ensino. No Problema 1, os estímulos utilizados eram três palavras da língua portuguesa (ditadas e impressas) e suas figuras representacionais; no Problema 2, eram três palavras sem sentido (ditadas e impressas) e três figuras abstratas. Apenas para três participantes (i.e., P3, P4 e P5), foram utilizadas pistas orofaciais associadas às tarefas de MTS O uso das pistas orofaciais, neste contexto, era um procedimento de correção e ocorria nos momentos em que o participante cometia algum erro, durante as tentativas de treino das relações condicionais. Eram aplicados testes de nomeação de figuras, antes e após cada problema de ensino. Cada bloco de teste foi composto por seis tentativas de nomeação de figuras, sendo três tentativas com as palavras empregadas no problema de ensino em vigor e, a fim de garantir certo nível de acertos, mais três palavras, presumivelmente conhecidas dos participantes. Em relação aos desempenhos, no Problema 1, no pré-teste de nomeação de figuras, os participantes P1, P2 e P4 obtiveram um acerto cada $(33,3 \%$ de acertos), em três tentativas de teste; P5 obteve dois acertos $(66,67 \%$ de acertos) e P3 emitiu respostas incorretas, em todas as tentativas. No pós-teste, P1, P3 e P5 emitiram duas respostas corretas $(66,67 \%$ de acertos), enquanto P2 e P4 obtiveram $100 \%$ de acertos. Em relação ao Problema 2, são demonstrados os dados de P1, P4 e P5. No pré-teste de nomeação, P1 e P5 não emitiram respostas corretas e P4 não foi exposto ao pré-teste. No pós-teste, P1 emitiu duas respostas corretas $(66,67 \%$ de acertos), ao passo que $\mathrm{P} 4 \mathrm{e}$ P5 emitiram uma reposta correta $(33,33 \%$ de acertos). Assim sendo, a análise dos dados parece indicar que o uso de pistas orofaciais, realizado com os participantes P3, P4 e P5, não resultou em maiores porcentagens de acertos, nos testes de nomeação, quando comparados aos participantes que não receberam as pistas orofaciais.

Em alguns experimentos, tarefas com requisição de respostas de vocalização eram utilizadas não apenas durante o procedimento de ensino, mas também para determinar as palavras que seriam empregadas como estímulos auditivos e/ou visuais, durante o estabelecimento da linha de base. Em termos gerais, esses procedimentos consistiam na aplicação de uma fase de pré-testes (e.g., Almeida-Verdu et al., 2012; AnastácioPessan, 2011; Battaglini et al., 2013; de Souza et al., 2010; de Souza et al., 2013) ou na realização de uma avaliação inicial (Golfeto, 2010). Em ambos os procedimentos, eram apresentadas, aproximadamente, 30 palavras da língua portuguesa (impressas e ditadas) e suas figuras representacionais. Os estímulos eram aplicados em 
tentativas que requeriam respostas vocais, (nomeação ou ecoico) ou repostas de seleção. Via de regra, para a fase de ensino, eram escolhidos os estímulos para os quais o participante emitisse respostas incorretas. Para os participantes que respondiam, corretamente, a maioria das tentativas desta fase, eram adotadas palavras sem sentido e figuras abstratas. Em alguns casos, os estímulos para os quais o participante emitisse respostas corretas eram utilizados como estímulos conhecidos.

Almeida-Verdu et al. (2012), por exemplo, conduziram um experimento com quatro indivíduos implantados, acometidos de deficiência auditiva prélingual. Para três indivíduos, a fase de ensino apresentou palavras sem sentido e figuras abstratas. Para uma participante (MAE), foram usadas palavras da língua portuguesa e suas figuras representacionais. Nos pós-testes de nomeação, cada uma das três figuras, utilizadas na fase de ensino, era exibida três vezes. No pós-teste, a participante MAE emitiu quatro respostas corretas, em nove tentativas de teste $(44,4 \%$ de acertos). Em relação aos resultados obtidos no pós-teste, pelos outros participantes, dois deles emitiram quatro respostas corretas (44,4\% de acertos) e um emitiu oito respostas corretas (88,8\% de acertos), também em nove tentativas de teste.

Do estudo de Battaglini et al. (2013), participaram cinco crianças com implante coclear, todas com deficiência auditiva pré-lingual. Apenas para um participante (JP) foi empregado um conjunto com duas palavras sem sentido (ditadas e impressas), duas figuras coloridas abstratas e uma palavra da língua portuguesa e sua figura representacional. Para os demais participantes, apresentaram-se conjuntos, com três palavras sem sentido e três figuras coloridas abstratas. Os testes de nomeação consistiram em um bloco, para avaliar a nomeação de figuras e outro bloco, para avaliar a nomeação de palavras impressas, cada um deles com nove tentativas. $\mathrm{Na}$ apresentação dos resultados do pós-teste, dois participantes, dentre eles JP, emitiram uma vocalização correta tanto em nomeação de figuras ( $11 \%$ de acertos), quanto em nomeação de palavras impressas $(11 \%$ de acertos). Um participante (MM) emitiu duas vocalizações corretas tanto para nomeação de figuras (22\% de acertos), quanto para palavras impressas (22\% de acertos). Um participante (LA) emitiu duas vocalizações corretas para nomeação de figuras (22\% de acertos) e três para nomeação de palavras impressas (33\% de acertos). Apenas um participante (GP) emitiu nove respostas corretas em nomeação de figuras e nove em nomeação de palavras impressas (100\% de acertos, em ambos os casos).

No Experimento 1, do estudo de Souza et al. (2010), foram avaliadas as performances de sete crianças implantadas, todas com deficiência auditiva pré-lingual. $\mathrm{Na}$ fase de ensino, foram estabelecidas relações condicionais, primeiramente entre palavra ditada e figura e, posteriormente, entre figura e palavra impressa. Nos pós-testes de nomeação, foram verificadas as vocalizações emitidas diante de figuras e de palavras impressas. Ao relatar os resultados dos pós-testes, os autores apontam que dois participantes emitiram vocalização com correspondência ponto a ponto, tanto em nomeação de figuras quanto de palavras; uma participante emitiu vocalização sem nenhuma correspondência e, finalmente, quatro participantes emitiram vocalizações com correspondência parcial.

Golfeto (2010), em seu Experimento 1, programou três problemas de ensino, para o treino das relações condicionais. No Problema 1, eram ensinadas relações condicionais entre palavras da língua portuguesa (impressas e ditadas) e suas figuras representacionais. Nos Problemas 2 e 3, eram utilizadas palavras sem sentido (impressas e ditadas) e figuras abstratas. Ao início e ao fim de cada um dos problemas de ensino, foram aplicados testes de nomeação de figuras, sendo um bloco com três tentativas para avaliar nomeação. Em relação aos resultados dos testes do Problema 1, a participante CM nomeou, com correspondência ponto a ponto, duas figuras (66,6\% de acertos), tanto no pré, quanto no pós-teste. A participante NT não acertou nenhuma, no pré-teste de nomeação e duas, no pós-teste $(66,6 \%$ de acertos). Nos testes do Problema 2, CM e NT não apresentaram nomeação correta, no pré-teste e, nos pós-testes, as participantes emitiram três nomeações corretas $(100 \%$ de acertos). Em relação aos testes do Problema 3, ambas as participantes emitiram uma nomeação correta, no pré-teste e três corretas, no pós-testes (100\% de acertos).

Anastácio-Pessan (2011) conduziu um estudo com seis crianças, com implante coclear: três deficientes auditivos pré-linguais e três pós-linguais. Foram conduzidas duas unidades de ensino, cada uma com um conjunto diferente de palavras e figuras. Para três participantes (GAB, VIV e LUA), na Unidade 1, eram utilizadas palavras da língua portuguesa e suas figuras representacionais. Para os outros três (GUS, TAL e TAM), eram utilizadas duas palavras da língua portuguesa e suas figuras representacionais, além de uma palavra sem sentido e uma figura abstrata. $\mathrm{Na}$ Unidade 2, para dois participantes (TAM e GUS), eram utilizadas duas palavras da língua portuguesa e suas figuras representacionais, bem como uma palavra sem sentido e uma figura abstrata. Para três participantes (GAB, VIV e TAL), optou-se por usar uma palavra da língua portuguesa e sua figura representacional e, também, duas palavras sem sentido e duas figuras abstratas. Para um participante (LUA), três palavras sem sentido e três figuras abstratas eram utilizadas. Antes e após cada condição de ensino, foi aplicado um teste de nomeação de figuras e de palavras impressas. Nestes testes, foram apresentadas as seis figuras e seis palavras impressas, das duas unidades de ensino, em um bloco com seis tentativas, para nomeação de figuras e mais seis tentativas, para nomeação de palavras impressas. Assim, nos quatro testes de nomeação, com os estímulos da Unidade 1, TAM (pós-lingual) não apresentou mais que dois acertos $(66,67 \%$ de acertos), tanto em nomeação de figuras, quanto de palavras. Em relação às palavras da Unidade 2 , não apresentou mais que dois acertos (66,67\% de acertos), nos sucessivos testes de nomeação de figuras e palavras. A participante VIV (póslingual) manteve $100 \%$ de acertos, nos sucessivos testes das Unidades 1 e 2. GAB (pós-lingual), nos sucessivos testes com palavras da Unidade 1, variou entre um e dois 
acertos (de 33,33\% a 66,67\% de acertos). Com as palavras da Unidade 2, GAB apresentou muita variabilidade, não atingindo mais que dois acertos $(66,67 \%$ de acertos). GUS (pré-lingual), tanto nos testes da Unidade 1, quanto nos testes da Unidade 2, demonstrou muita variação nos dados, tendo entre um e três acertos $(33,3 \%$ a $100 \%$ de acertos), com o melhor desempenho, nos últimos testes de cada unidade. TAL (pré-lingual), nos testes com palavras da Unidade 1, variou entre dois e três acertos $(66,67 \%$ a $100 \%$ de acertos). Com as palavras da Unidade 2, também oscilou entre dois e três acertos $(66,67 \%$ a $100 \%$ de acertos). Em ambos os casos, os melhores resultados foram após o ensino das relações entre palavra ditadas e impressas. A participante LUA (pré-lingual) variou entre um e dois acertos, ao longo dos testes da Unidade 1 $(33,33 \%$ a $66,67 \%$ de acertos). Nos testes com palavras da Unidade 2, variou entre dois e três acertos $(66,67 \%$ a $100 \%$ de acertos). Os melhores desempenhos desta participante foram após o ensino das relações condicionais entre palavra ditada e figura e entre palavra ditada e impressa.

De Oliveira (2013) conduziu uma pesquisa com quatro crianças, com implante coclear, todas deficientes auditivas pré-linguais. Foram ensinadas relações condicionais entre movimentos orofaciais e figuras e entre palavras ditadas e figuras. Como estímulos, foram utilizadas oito palavras da língua portuguesa (ditadas e impressas) e suas figuras representacionais. Foram aplicados três testes de nomeação de figuras. O primeiro teste foi realizado após o ensino da primeira relação condicional. O segundo teste ocorreu após o ensino da segunda relação condicional e o terceiro teste foi aplicado após o ensino simultâneo das duas relações condicionais. Os testes de nomeação de figuras foram compostos por blocos com 16 tentativas, sendo oito para verificar a nomeação de figuras e, a fim de garantir certo nível de acertos, oito com relações condicionais ensinadas, durante a linha de base. No primeiro teste de nomeação, a participante LCA acertou cinco tentativas em oito, $62 \%$ de acertos. No segundo teste, LCA acertou três tentativas, $38 \%$ de acertos. No terceiro teste, LCA acertou seis tentativas, $75 \%$ de acertos. A participante JSS acertou, no primeiro teste de nomeação, seis tentativas, $75 \%$ de acertos. No segundo e terceiro testes de nomeação de figuras, JSS acertou sete tentativas, $88 \%$ de acertos. O participante NSS acertou, apenas, duas tentativas em cada um dos três testes realizados, $25 \%$ de acertos. No primeiro teste, a participante ACP acertou cinco tentativas, $62 \%$ de acertos. No segundo e terceiro testes de nomeação de figuras, ACP acertou quatro tentativas, $50 \%$ de acertos em cada teste.

O estudo de Souza et al. (2013) contou com quatro participantes implantados, todos deficientes auditivos pré-linguais. Para o estabelecimento da linha da base, no caso de três participantes, foram utilizadas palavras da língua portuguesa e suas figuras representacionais. Para um participante (HLO), foram utilizadas, além das palavras da língua portuguesa e as figuras representacionais, palavras sem sentido e figuras abstratas. Foram conduzidos dois testes de nomeação, ao longo do procedimento. O primeiro ocorreu após o ensino das relações condicionais entre palavras ditadas e figuras e o segundo ocorreu na sequência ao ensino do comportamento ecoico. Os testes de nomeação de figuras eram compostos por um bloco com nove tentativas, três tentativas para cada figura da fase de ensino. No primeiro teste de nomeação, HLO emitiu sete nomeações corretas (77,7\% de acertos). No segundo teste, o mesmo participante emitiu seis nomeações corretas $(66,6 \%$ de acertos). Além disso, HLO foi exposto a um terceiro teste de nomeação, no qual emitiu oito respostas corretas (88,8\% de acertos). No primeiro teste, a participante LRS emitiu duas respostas corretas (22,2\% de acertos); no segundo, emitiu seis respostas corretas $(66,6 \%$ de acertos). $\mathrm{O}$ participante BRN emitiu sete respostas corretas, no primeiro teste $(77,7 \%$ de acertos) e nove respostas corretas, no segundo teste ( $100 \%$ de acertos). Por fim, o participante JOP respondeu, corretamente, três tentativas, no primeiro teste $(33,3 \%$ de acertos) e respondeu, corretamente, cinco tentativas do segundo teste $(55,5 \%$ de acertos).

A variabilidade observada quando analisados, em conjunto, os resultados obtidos em cada experimento, parece indicar que a escolha prévia de palavras a partir do repertório inicial dos participantes (i.e., utilização de testes de nomeação para a escolha de palavras a serem utilizadas no ensino de relações condicionais), independente do fato de serem palavras e figuras na língua portuguesa ou palavras sem sentido e figuras abstratas, porquanto não interferiram, de forma positiva, com os resultados obtidos, nos testes de nomeação realizados após a intervenção.

\section{CONSIDERAÇÕES FINAIS}

Quando consideramos os trabalhos em que são ensinadas relações condicionais entre palavras ditadas e palavras impressas, para crianças com atraso escolar (de Rose, de Souza, \& Hanna, 1996; de Souza \& de Rose, 2006; de Souza, de Rose, \& Domeniconi, 2009; Serejo, Hanna, de Souza, \& de Rose, 2007; Reis, de Souza, \& de Rose, 2009), nota-se que os resultados dos testes de nomeação de palavras impressas são mais promissores, se comparados aos resultados dos estudos com implantados, em que foram realizados testes de nomeação de figuras e/ou palavras impressas (Almeida-Verdu, Huziwara, et al., 2008; Almeida-Verdu, dos Santos, et al., 2008; AlmeidaVerdu, et al., 2009; Almeida-Verdu, et al., 2012; Anastácio-Pessan, 2011; Battaglini, et al., 2013; de Souza, et al., 2010; de Souza, et al., 2013; Golfeto, 2010; Oliveira, 2013; Passarelli, et al., 2013.). Diante disto, é possível questionar: por que procedimentos de matchingto-sample parecem ser mais eficazes para instalar comportamentos de nomeação em crianças com atraso escolar do que em crianças com implante coclear? Seria uma deficiência nos procedimentos programados? Ou uma limitação do matching-to-sample para ensinar comportamentos de nomeação a crianças com implante coclear? Seria um conjunto de variáveis que ainda não foram consideradas e interferem nos resultados dos testes de nomeação, aplicados em crianças com implante coclear? 
Questões sobre quão independentes são os comportamentos de ouvir e falar, ou até que ponto a nomeação de estímulos favorece o estabelecimento de relações de equivalência, podem subsidiar pesquisas futuras. Além disto, estas questões e as pesquisas delas decorrentes podem contribuir para o desenvolvimento de tecnologias de ensino que propiciem à população de implantados a aquisição de comportamentos de ouvir e falar, de maneira ágil e eficiente, ocorrendo sem erros, através de contingências reforçadoras de ensino.

Vale ressaltar que a tecnologia de ensino atual é muito eficiente para estabelecer repertório receptivo, mas não tão eficiente para estabelecer comportamentos associados à leitura expressiva. Tal fato é evidenciado pela comparação dos resultados entre os testes de equivalência e de nomeação (ver tabela 4). Os participantes apresentaram melhores resultados nos testes que envolviam seleção de figuras e de palavras impressas ambos repertório receptivo -, quando comparados aos resultados atingidos nos testes de nomeação de figuras e de palavras impressas, constituindo, ambos, comportamentos associados à leitura expressiva. Desta forma, percebe-se como são necessários avanços tecnológicos nos procedimentos de ensino que se propõem a instalar e manter comportamentos associados à leitura expressiva, a ponto de serem tão eficazes quanto os procedimentos que instalam e mantêm repertório receptivo.

Ao avaliar o desenvolvimento dos repertórios de nomeação, imitação de palavras e reconhecimento de palavras, em recém implantados, o estudo de Gaia (2005) fomentou a discussão sobre a necessidade de se programarem contingências de ensino mais eficazes, para esta população. A autora aplicou três testes, consecutivos, de comportamento ecoico, de nomeação e de reconhecimento de palavras, com um intervalo de cinco meses entre eles. Ao longo dos sucessivos testes, observou-se um aumento, gradual e significativo, no reconhecimento de palavras e menos expressivo para a nomeação e comportamento ecoico. Contudo, as análises das respostas de nomeação e de ecoico demonstram uma enorme queda nas "não respostas" e um aumento, nas nomeações com correspondência parcial. Tais evidências demonstraram que implantados apresentam altos índices de aprendizagem, relacionados aos comportamentos de reconhecimento de palavras e de seleção de figuras. Todavia, os baixos escores de nomeação com correspondência ponto a ponto apontavam para a necessidade de pesquisas sobre contextos de ensino mais eficientes para a instalação e a manutenção dos comportamentos de ecoico e nomeação.

De Morais (2013) também aponta para tal necessidade, ao analisar os padrões de erros cometidos por implantados. Para tanto, após uma avaliação inicial, aplicou um pré-treino - ensino de relações condicionais entre estímulos visuais e auditivos e pós-testes de ecoico, de nomeação e de reconhecimento de palavras. Interessante notar que, para analisar os resultados dos póstestes, De Morais estabelece diferentes categorias, a saber: número de silabas; padrão de sílaba tônica; fonema inicial; fonema final; produção das vogais; produção de fonemas/alofones. Ao discutir os resultados, a autora aponta que existem diferentes padrões de erros e acertos, nas performances dos implantados. As características específicas de cada palavra controlam diferentes aspectos da fala do implantado. Isto demonstra que é essencial se programarem formas de aprendizagem que considerem unidades mínimas do estímulo, no caso de palavras. Estas unidades seriam as letras, as sílabas, os fonemas, etc.

Ainda vale ressaltar o aumento nas pesquisas sobre as programações de ensino mais eficazes para os estabelecimentos dos comportamentos de ecoico, nomeação e reconhecimento de palavras. Dentre as pesquisas aplicadas, destacamos a publicação de AlmeidaVerdu e Golfeto (2012), direcionada para pais e profissionais interessados em condições para o ensino da linguagem e, também, a de Almeida-Verdu (2012), direcionada a cuidadores e familiares. No campo das pesquisas básicas, estudos mais recentes buscam determinar como ocorre o estabelecimento dos comportamentos de nomeação. Podemos destacar Anástacio-Pessan, Almeida-Verdu, Bevilacqua, de Souza, (no prelo) e Antonelli, Girotto, Neves, Almeida-Verdu (no prelo).

Assim sendo, ao longo dos anos, muitas contribuições foram fornecidas, no que se refere ao ensino de repertórios comportamentais receptivos, em implantados (p. ex., tarefas de seleção de estímulos visuais diante palavras ditadas e reconhecimento de palavras). A partir do conhecimento gerado, torna-se oportuno e necessário investigar o ensino de repertórios comportamentais expressivos, como o comportamento ecoico e a nomeação de palavras impressas e figuras. Ao expor os implantados a relações coerentes entre palavras ditadas, impressas e seus respectivos referentes (figuras, símbolos, pessoas, bonecas, dentre outras), tanto de forma receptiva quanto expressiva, há uma maior probabilidade de eles se tornarem hábeis, cada vez mais, ao se aproveitarem dos benefícios do implante coclear.

\section{REFERÊNCIAS}

Almeida, C. G. M., Battaglini, M. P., \& Almeida-Verdu, A. C. M. (2009). Comportamento verbalmente controlado: Algumas questões de investigação do controle por estímulos textuais e pela palavra ditada. Em T. G. M. Valle (Org.), Aprendizagem e desenvolvimento humano: Avaliações e intervenções (pp. 9-32). São Paulo: Cultura Acadêmica.

Almeida-Verdu, A. C. M. (2004). Funções simbólicas em pessoas submetidas ao implante coclear: Uma análise experimental do ouvir (Tese de Doutorado). Universidade Federal de São Carlos, São Carlos.

Almeida-Verdu, A. C. M. (2012). Procedimentos para o desenvolvimento do comportamento de ouvir em crianças com deficiência auditiva e implantadas. Em L. E. Melchiori, O. M. R. Rodrigues, \& A. C. Bortolozzi (Orgs.), Cuidados com a criança e com a família reflexões teóricopráticas (pp. 1-60). Curitiba: Juruá. 
Almeida-Verdu, A. C. M., Bevilacqua, M. C., de Souza, D. G., \& de Souza, F. C. (2009). Imitação vocal e nomeação de figuras em deficientes auditivos usuários de implante coclear: Estudo exploratório. Revista Brasileira de Análise do Comportamento, 5, 63-78.

Almeida-Verdu, A. C. M., dos Santos, S. L. R., de Souza, D. G., \& Bevilacqua, M. C. (2008). Ouvir e falar: Repertório de comunicação em surdos que receberam o implante coclear. Revista Eletrônica Núcleos de Ensino, 8, 902-913.

Almeida-verdu, A. C. M., \& Golfeto, R. M. (2012). Condições de ensino da linguagem: Dicas para pais e profissionais. Bauru: Joarte.

Almeida-Verdu, A. C. M., Huziwara, E. M., de Souza, D. G., de Rose, J. C., Bevilacqua, M. C., Lopes Jr., J., Alves, C. O., \& McIlvane, W. J. (2008). Relational learning in children with deafness and cochlear implants. Journal of the Experimental Analysis of Behavior, 89, 407-424. doi: 10.1901/jeab.2008-89-407

Almeida-verdu, A. C. M., Matos, F. O., Battaglini, M. P., Bevilacqua, M. C., \& de Souza, D. G. (2012). Desempenho de seleção e nomeação em crianças com deficiência auditiva com implante coclear. Temas em Psicologia, 20, 189-202.

Anastácio-Pessan, F. L. (2011). Evolução da nomeação após fortalecimento de relações auditivo-visuais em crianças com deficiência auditiva e implante coclear (Dissertação de Mestrado). Universidade Estadual Paulista “Júlio Mesquita Filho", Bauru.

Anastacio-Pessan, F. L., Almeida-Verdu, A. C. M., Bevilacqua, M. C., \& de Souza, D. G. (no prelo). Usando o Paradigma de Equivalência para Aumentar a Correspondência na Fala de Crianças com Implante Coclear na Nomeação de Figuras e na Leitura. Psicologia: Reflexão e Crítica,

Antonelli, C. S, Girotto, M., Neves, A. J., \& AlmeidaVerdu, A. C. M. (no prelo). Efeitos da aprendizagem da relação entre palavra ditada e figura sobre a nomeação de figuras: Relações entre o ouvir e o falar. Psicologia em Revista.

Battaglini, M. P., Almeida-Verdu, A. C. M., \& Bevilacqua, M. C. (2013). Aprendizagem via exclusão e formação de classes de equivalência em crianças com deficiência auditiva e implante coclear. Acta Comportamentalia, $21,20-35$.

Bevilacqua, M. C. (1998). Implante coclear multicanal: Uma alternativa na habilitação de crianças surdas. (Tese de livre-docência). Bauru: Universidade de São Paulo.

Brazorotto, J. S. (2008). Crianças Usuárias de implante coclear: Desempenho acadêmico, expectativa dos pais $e$ dos professores (Tese de Doutorado). Universidade Federal de São Carlos, São Carlos.
Catania. A. C. (2008). Aprendizagem: comportamento, linguagem e cognição. (de Souza, D. G. et al., Tard..) ( $4^{\mathrm{a} e d}$.) Porto Alegre: Artes Médicas Sul.

Danieli, F. (2010). Reconhecimento de fala com e sem ruído competitivo em crianças usuárias de implante coclear utilizando dois diferentes processadores de fala (Dissertação de Mestrado). Universidade Federal de São Carlos, São Carlos, SP, Brasil.

de Morais, M. A. S. (2013). Avaliação das vocalizações de crianças usuárias de implante coclear (Dissertação de Mestrado). Universidade Federal de Minas Gerais. Belo Horizonte.

de Oliveira, J. A. (2005) Implante Coclear. Revista Médica, 38, 262-272.

de Rose, J. C. C. (1993). Classes de estímulos: Implicações para uma análise comportamental da cognição. Psicologia: Teoria e Pesquisa, 9, 283-303.

de Rose, J. C., de Souza, D. G., \& Hanna, E. S. (1996). Teaching reading and spelling:

Exclusion and stimulus equivalence. Journal of Applied Behavior Analysis, 29, 451-469.

de Souza, F. C., Almeida-Verdu, A. C. M., \& Bevilacqua, M. C. (2013). Ecoico e nomeação de figuras em crianças com deficiência auditiva pré-lingual com implante coclear. Acta Comportamentalia, 21, 325339.

de Souza, D. G., Golfeto, R. M., Almeida-Verdu, A. C. M., Battaglini, M. P., Bevilacqua, M. C. \& de Oliveira, T. P. (2010) Controle de estímulos e comportamento verbal em deficientes auditivos: Estudo das relações entre o ouvir e o falar. Em M. M. C. Hubner et al. (Orgs.), Sobre Comportamento e Cognição, Análise Experimental do Comportamento, cultura, questões conceituais e filosóficas, 25, 259-270.

de Souza, D. G., \& de Rose, J. C. (2006). Desenvolvendo programas individualizados para o ensino de leitura. Acta Comportamentalia, 14, 77- 114.

de Souza, D. G., de Rose, J. C., \& Domeniconi, C. (2009). Applying relational operants to reading and spelling. Em R. A. Rehfeldt e Y. Barnes-Holmes (Eds.), Derived relational responding: Applications for learners with autism and other developmental disabilities, 171-207.

Dixon, L. S. (1977). The nature of control by spoken words over visual stimulus selection. Journal of the Experimental Analysis of Behavior, 27, 433-442. doi: 10.1901/jeab.1977.27-433

Gaia, T. F. (2005). Avaliação do repertório verbal inicial em crianças com deficiência auditiva pré-lingual usuárias de implante coclear (Dissertação de Mestrado). Universidade Federal de São Carlos, São Carlos.

Golfeto, R.. M. (2010). Compreensão e produção de fala em crianças com surdez pré-lingual usuárias de 
implante coclear (Tese de Doutorado). Universidade Federal de São Carlos, São Carlos, SP, Brasil.

Goyos, C., Rossit, R. A. S., Elias, N. C., Escobal, G., \& Chereguini, P. (2009). Análise do comportamento e o estudo do envelhecimento humano: revisão dos estudos de aplicação. Revista Brasileira de Análise do Comportamento, 5(2), 1-20.

Hall, R. V. (1974). Managing behavior - behavior modification: The measurement of behavior. Lawrence, Kansas: H \& H Enterprises.

Lima Jr., L. R. P., Rodrigues Jr., F. A., Calhau, C. M. D. F., Calhau, A. C. D. F., \& Palhano, C. T. P. (2010). Postoperative Complications in implanted patients in the Cochlear Implant Program of Rio Grande do Norte - Brazil. Revista Brasileira de Otorrinolaringologia, 76(4), 517-521.

Oliveira, S. R. (2013). Avaliação de fala de usuários de implante coclear após ensino de relações modelo articulatório/figura e palavra falada/figura (Dissertação de Mestrado). Universidade Federal de São Carlos, São Carlos, SP, Brasil.

Passarelli, A. C. P. M., de Oliveira, T. P., Golfeto, R. M., Cardinali, R., de Rezende, J. V., \& Fenner, M. C. (2013). Discriminação auditivo visual com pistas orofaciais em crianças deficientes auditiva. Acta Comportamentalia, 21, 175-192.

Serejo, P., Hanna, E. S., de Souza, D. G., \& de Rose, J. C. C.(2007). Leitura e repertório recombinativo: efeito da quantidade de treino e da composição dos estímulos. Revista Brasileira de Análise do Comportamento, 3(2), 191-215.
Sidman, M. (1971). Reading and auditory-visual equivalences. Journal of Speech and Hearing Research, 14, 5-13.

Sidman, M. (1994). Equivalence relations and behavior: A research story. Boston: Authors Cooperative.

Sidman, M. (2000). Equivalence relations and the reinforcement contingency. Journal of the Experimental Analysis of Behavior, 74, 127-146. doi 10.1901/jeab.2000.74-127

Sidman, M., \& Tailby, W. (1982). Conditional discrimination vs. matching to sample: An expansion of the testing paradigm. Journal of the Experimental Analysis of behavior, 37, 5-22. doi 10.1901/jeab.1982.37-5

Silva, R. C. L., \& Araújo, S. G. (2007). Os resultados do implante coclear em crianças portadoras de neuropatia auditiva: Revisão de literatura. Revista da Sociedade Brasileira de Fonoaudiologia, 12, 252-257.

Reis, T. S., de Souza, D. G., \& de Rose, J. C. (2009). Avaliação de um programa para o ensino de leitura e escrita. Estudos em Avaliação Educacional, 20, 425450 .

Submetido em 14/11/2014. Aceito em 06/04/2015. Publicado em 01/02/2016. 